\title{
Inhuman Rights: Components of Spectrality in Anil's Ghost
}

\author{
Jan Gresil S. Kahambing \\ Leyte Normal University, Tacloban City, Philippines, vince_jb7@hotmail.com, ORCID: \\ oooo-0002-4258-0563
}

\begin{abstract}
Human rights discourse in Ondaatje's novel Anil's Ghost is premised in the insistence of seeking responsibility for the deaths of the victims and viewing them within a shared sense of humanity. Although inserted with throwbacks, there is a linearity in the text that proceeds with Anil and Sarath seeking Sailor's human identity. Taking an alternative from this linear fashion, this paper presents the discourse of rights within an inhuman or spectral turn. To do this, the paper exposes some components of spectrality or spectralizations in the novel, namely: 1) Plural and Re-SriLankanized Spectrality, 2) Good and Bad Spectrality, and 3) Delirious Spectrality, and how these reflect further the inhuman or spectral character of rights.
\end{abstract}

Keywords: Humanity, Rights, Anil's Ghost, Spectrality, Inhuman

\section{The Spectral Turn of Human Rights in Anil's Ghost}

Human rights discourse in Ondaatje's novel Anil's Ghost centers its premise on the problem of the human. The text reveals the crucial predicament that dictates the movement of the characters: 'the problem up here is not the Tamil problem, it's the human problem (Ondaatje, 2000, 111; Henceforth, AG).' The element of the human that is buried in the conceptions of the victims drives Anil and Sarath into acts of making such humanity known along with the fundamental rights that come with it. However backed with insertions of memory, seen in the use of throwbacks (e.g. Anil's break-up with Cullis, Lakma's story, Palipana's career), the text generally proceeds with a linear progression of seeking responsibility for the deaths of the victims as represented by Sailor and viewing them within a shared sense of humanity. Albeit perilous, their acts of uncovering, unearthing, or bringing into fore the lucid violations of human rights are critical turns where rights are viewed within a human frame, and on the outset, within a universal moral order. While the 'practical discourse of human rights claims the burden of safeguarding the most fundamental features and conditions of our humanity (Cheah, 2006, 145),' this paper presents an alternative process of this discourse in a 'spectral turn,' one which exposes the inhuman or spectral character of rights. To proceed with this process, the question that shall frame the paper is not 'how does the discourse of human rights reveal the problem of humanity in the text?' but 'how does the inhuman or spectral turn in the text problematize the discourse of rights?'

This spectral turn 'may be read not only as a turn to the spectral, but also as the spectralization of the turn-its unmooring from defined points of departure, notions of linear

(C) AesthetixMS 2019. This Open Access article is published under a Creative Commons Attribution Non-Commercial 4.0 International License (http://creativecommons.org/licenses/by-nc/4.o/), which permits non-commercial re-use, distribution, and reproduction in any medium, provided the original work is properly cited. For citation use the DOI. For commercial re-use, please contact editor@rupkatha.com. 
progress, and fixed destinations (Blanco and Peeren, 2013, 32).' Throughout the plot, this would mean disturbing the understanding that Anil is working within the exact protocols of Human Rights from Geneva (cf. AG, 12). The specifics of this spectralization can be seen from the moment Anil tried to assert her practice and Sarath making her realize that such can no longer work.

Anil: Some people let their ghosts die, some don't. Sarath, we can do something. ...'

Sarath: 'You're six hours away from Colombo and you're whispering-think about that.' $(\mathrm{AG}, 28)$

In this sense, spectrality means that something goes uncanny 'not for us, but being accustomed to the strange graveyards we are subjected (Clinton, 2012, 20; Italics mine).' From the moment she went back to Sri Lanka, the universal protocols of human rights are already rendered ineffective against the strange graveyard she is in, characterized by 'continual emergency from 1983 onwards, racial attacks and political killings (AG, 23).' This is contextualized as an inhuman national condition Sarath can only describe in his words: 'Everyone's scared, Anil. It's a national disease $(A G, 28)$.' The linear modality of the text, expressed in the drive that they have to identify Sailor to make him a victim (cf. AG, 82), becomes 'spectral' or 'ghostly' as the term suggests (cf. Shin, 2013, 2) when Anil's strategy now blurs her career and crosses the boundary of her practice.

This notion of spectrality as a new turn in the operation of Anil hinges not only on the cultural contextualization of Sri-Lanka but also of criticizing the 'cultural instrumentalities' that 'produce and regulate the nation state by making its repressed narratives insubstantial (Turcotte, 2008, 7)' and by 'masking the social relations' of what is really happening (Clinton, 2012, 38). What spectrality initially uncovers is a fundamental law that contaminates the living, which Sarath mentions is fear (cf. AG, 65). With the implication of not knowing what shall happen to one's life, or the deaths of many, Ondaatje writes: 'In a fearful nation, public sorrow was stamped down by the climate of uncertainty $(A G, 29)$.' It is fear that regulates the living, so that the place, even hours away from the center, is haunted by the ghosts that constitute the lives of the people, lives that also have become inhuman or spectral - lives 'perpetually haunted by the spectrality from within that constitutes it (Cheah, 2006, 118).'

To understand spectrality further as it rests on Anil as a representative of Human Rights working within a spectral turn, the following sections shall delve into the text with the components of the spectral and how these relate to the problematizing of rights as inhuman or spectral. By component, one means the mechanisms or spectralizations through which spectrality operates. Some studies either view it with regard to 'temporality, origin, reason/unreason, and representation (Chen, 2002, 234)' or into 'frequency: number (more than one), insistence, rhythm (waves, cycles, and periods) (Derrida, 1994, 133).' Drawing from such as guide, rather than as blueprint, this paper navigates in some sense through the components in terms of number, origin, representation, and insistence, which more or less translate into a branding of the components as 1) Plural and Re-SriLankanized Spectrality, 2) Good and Bad Spectrality, and 3) Delirious Spectrality.

\section{Plural and Re-Sri Lankanized Spectrality}

In terms of number and origin, one can analogize and rebrand the kinds of spectralizations Cheah mentioned (Cheah, 2006, 133-134). In terms of number, there is a so-called plural society type of spectralization. The idea is that there is, for the Chinese merchants or overseas Chinese of colonial states, a universalized term 'Chinese' that takes its survival form from a colonial policy 
even without the ethos of their original Chinese counterparts, a spectral 'Chineseness' that adapts in a colonial sense but paradoxically points to the fixed idea of Chinese. Within the context of the text, is not this plural society type of spectrality exposed precisely in the construction of the human victim caught between the killing field of the government and the insurgents? The idea is that what survives in the continual ironclad field of killings is the universal term 'victim,' a spectral 'victimness' that although does not fully identify to the aspirations of each camp, represents nonetheless the plurality of humanity. It is in this sense that Anil goes on to find out the 'murder victim,' names it Sailor, and seeks to identify him, a 'victim among thousands,' in hopes of 'speaking about human rights' that 'one village can speak for many villages. One victim can speak for many victims (cf. AG, 27, 44, 125).' In a plural spectralization, there is a universal belongingness of the victims, capped in the hopes of Anil.

Anil hopes that the examination of the Sailor skeleton can produce evidence against those in power. This means that he could be one of those speaking for the other thousands of victims. At the same time Sailor is Everyman, as the name suggests (History of Sri Lanka in Anil's Ghost, 2017, 69).

Here, the plural spectrality of rights discourse takes the imperative of hearing the victims as the 'plural dead' (Kambuoreli, 2008 28).' Anil's seeking the rights of Sailor is a turn to the plural spectrality of 'victimness', for 'without identifying Sailor, they had no victim yet (AG, 82).' Within this turn, even the representatives of human rights are not exempted. One instance points to the incidence where 'a human rights lawyer was shot and the body removed by army personnel (AG, 23).' Subsequently, no action has been taken from the previous representatives who have been there as if no intervention happened at all.

In terms of origin, one can analogize the other type of spectralization that emerged by running 'counter to this plural society type of spectralization,' in which the central thrust is 'reSinicization (Cheah, 2006, 133).' The main point was that the 'overseas Chinese were not Chinese enough' so that they had to undergo a 're-nationalization' through renewed contact with China. The same is true of Sarath's critique of human rights representatives:

His main critique of UN agents like Anil is that they seek to disclose "the truth" about human rights violations, but remain immune to the dangerous consequences that some truths-ostensibly positivist and neutral-may have for people living under the repressive government that the investigation targets (Babcock, 2014, 68-69).

What this spectrality projects is that Anil, after having been away for fifteen years from Sri-Lanka, had also to undergo a kind of 're-SriLankanization', a re-SriLankanized spectrality through renewed contact with Sri Lanka. What makes Anil's case different apart from any other human rights representatives who are sent as an international intervention is that she is from Sri Lanka, which led her not to expect to be chosen 'because she had been born on the island (AG, 12).' In this case, spectrality is 'not an imposition from the outside but the constitutive openness of any finite body (Cheah, 2006, 141).' It is a 'spectral process of paradoxical incorporation (Cheah, 2006, 126)': outside and yet from within. Anil had to reacquaint herself in the place for 'the island no longer held her by the past,' as she had lived 'abroad long enough to interpret Sri Lanka with a long-distance gaze (AG, 10).' Nonetheless, the element of re-SriLankanized spectrality was present in Anil: she was 'glad to be back, the buried senses from childhood alive in her (AG, 10).' The crucial turn of this is when Anil finally acknowledged her origin as well:

Sarath in the back row, unseen by her, listened to her quiet explanations, her surefootedness, her absolute calm and refusal to be emotional or angry. It was a lawyer's 
argument and, more importantly, a citizen's evidence; she was no longer just a foreign authority. Then he heard her say, 'I think you murdered hundreds of us.' Hundreds of us. Sarath thought to himself. Fifteen years away and she is finally us (AG, 123).

In the discourse of rights, this re-SriLankanized spectrality makes it possible for critiques of distancing move closer, that is to say within a closure, where the incorporation of rights is paradoxically not only of universal belongingness, as in plural spectrality, but also of 'renationalized' belongingness. While the usual call for responsibility is for human rights to instill a global moralist standpoint, the spectral turn of this is to prioritize rights both from the plurality of the victim's standpoint more than moral implications, and from the nationalized standpoint more than globalized considerations.

\section{Good and Bad Spectrality}

In terms of representation, one can read 'Pramoedya's distinction between good and bad spectrality' which 'presupposes that the spectral is a secondary or subordinate phenomenon that either derives or deviates from a more actual and original living ground (Cheah, 2003, 289).' The understanding of a specter as an absence made present (Anderson, 2008, 308; cf. Brogan, 1998, 25) can be read when the components of spectrality aims to 'trouble, uncover, and interrogate' (cf. Cameron, 2008, 383), hence, to subordinately represent in this case the actual discourse of rights that is becoming inhuman within the process of spectralization. The idea is that the manner of representation is labeled as good and bad at the level of organismic logic (Cheah, 2003, 302).

On the one hand, bad spectrality in this logic is a form of techne that cannot be converted and returned back to life. It is the mummification of human reason, as false as artificial teeth (Cheah, 2003, 299).' This bad spectralization speaks for instance 'of the impossible objectification and dehumanization of humans (Nayar, 2016, xiv).' In the text, this not only points to the material constituents of this objectification or these techne for dehumanization: the improved weapons, the 'international weaponry smuggled into country by arms dealers', 'homemade bombs', street bombs, 'bombs with everything to make sure you get gangrene from explosions,' 'mines, grenades, mortar shells (AG, 57, 63, 77; see also Sarkar, 2017).' It also points to the whole ironclad system of killings, the scene of the war itself: 'there was blood everywhere. A casual sense of massacre (AG, 128).' And this bad spectrality contaminates the people who are involved. Anil remembers for instance a woman at the Nadesan Center who said to her: 'I got out of the Civil Rights Movement partly because I couldn't remember which massacre took place when and where... (AG, 128).' The skeletons and dead bodies that are by-products of this spectrality are against the rational scene of human rights. The living too, within this field, are alive as inhuman ornaments: 'For everyone in the region was poor as grass', with the 'most frequently seen problems' of 'snakebites, rabbies caused by fox or mongoose, kidney failure, encephalitis, diabetes, tuberculosis', and the 'real problem of water (AG, 110).' They have become instruments of a 'lapsed state of reason,' signaling the dehumanizing techne that spectralizes the discourses of rights (cf. Cheah, 2003, 302).

On the other hand, good spectrality 'refers to the generation of a critical native public sphere' (Cheah, 2003, 289). In a postcolonial reading, good spectralization operates on the 'means for rearticulating the nation-people, for imagining new political solidarities that can resist and ultimately transcend the colonial state and even the circuit of global capital (Cheah, 2003, 289).' While in Pramoedya's Buru Quartet, good spectrality refers to the making of the vernacular press, in Anil's Ghost, good spectrality resides in the critical involvement of books and the practice of inscribing critical marginalia over them. The point is that there must already be a supposed 
disappearance of this practice within the state of killings. Here, Sirissa's disappearance takes the example of the disconnection from education, detached from the school and the books she reads in the evenings, no longer finding a drawing of her by her husband 'on a frail piece of paper he had tucked into the later reaches of the book's plot (AG, 81).' And yet the usage of books is reincarnated as it survives, or more precisely, it became the survival mechanism between life and death through which the characters took solace from. They remained and are actualized in the living. This is seen as Anil's way of seeking comfort amid the bad spectrality surrounding her, reading books like In Search of Gandhi by Richard Attenborough, and a life of Frank Sinatra (AG, 31). Palipana too 'lived in the forest grove with his books and writing tablets (AG, 42).' In the doctors' common room, the books of 'Erle Stanley Gardner, Rosemary Rogers, James Hilton, and Walter Tevis - were consumed in two or three hours, swallowed like sandwiches on the run. Anything to direct your thoughts away from a war (AG, 57).' In the Archaeological Offices, the books and maps were also needed in the investigation, with Sarath also bringing his favorites (cf. AG, 73; 77). In the hospitals, the habit of critical marginalia is practiced by Skanda the surgeon while defacing books: medical texts or novels $(A G, 105)$. The good spectrality that is found in the doctors is a way of transcending bad spectrality. In Skanda's words: 'The important thing is to be able to live in a place or a situation where you must use your sixth sense all the time (AG, 105).'

In the discourse of rights, bad spectrality dehumanizes the field, while good spectrality transcends it by critically assessing the situation, a survival form that runs counter to bad spectrality. However, it is unsafe to say that good and bad spectrality are exclusive opposites. The 'object or issue that is deemed ghostly falls under an axiological lens, to be either exorcized from or rejoined with the living in the end (Shin, 2013, 21).' That is to say, that these two are manners of representations, two sides of the same coin, and therefore spectralizations that only need critical assessment. Bad spectrality in this manner only needs to be exorcised (Cheah, 2003, 289). In Cheah's words: 'Although the bad spectrality of instrumental reason is an inevitable trait of enlightenment, it is merely a degraded or lapsed state of reason that can be corrected by final recourse to the light of self-recursive, organismic critical reason (Cheah, 2003, 302).' In this sense, bad spectrality can become good spectrality when techne becomes organicized, drawing from the organismic logic that 'organic life is itself inconceivable without some recourse to techne (Cheah, 2003, 304).'

What can further describe this bad-gone-good spectrality? At the end of the novel, Ananda 'as an artificer' is a beholder of a techne. 'But he knew if he did not remain an artificer he would become a demon. The war around him was to do with demons, spectres of retaliation (AG, 137).' Ananda's role is crucial in that he is left with the task of exorcising the bad specters and cleansing them into good specters. Drawing from good spectrality where techne becomes organicized (Cheah, 2003, 304), the task of reconciliation lies in the hands of Ananda by aestheticizing the war-torn country with the figure of the two Buddha statues (cf. Ratti, 2004). On the one hand, bad spectrality can be seen in the first Buddha, a statue surrounding the supposed 'neutral and innocent fields' that have now become 'places of torture and burials (AG, 135).' The Buddha was smashed into the ground, in the fields where Buddhism 'met the harsh political events of the twentieth century.' On the other hand, good spectrality can be seen in the other statue of the new Buddha 'a quarter of a mile away.' The building of this new statue rising anew stands as the critical view of a new horizon to be seen and enjoined by the living. But the crucial turn here is not the emergence of the new statue, but of the reconstruction of the large broken Buddha, of the eyes that 'had seen the wars and offered peace or irony to those dying under it $(A G, 137)$.' It is this statue and its brand new eyes that is able to transcend the bad spectralization done with it: now that it is exorcised of the specters of retaliations it was reconstructed from, it 
now stands in rejoining the living to see the 'seduction' of another 'angle of the world (AG, 138).' Moreover, Ananda had wanted the same calm and peacefulness he depicts from his wife, Sirissa, in his reconstruction of victims (cf. AG, 87), even of the broken Buddha statue, to reflect a good spectrality 'invented for her in the vacuum of her disappearance (AG, 139).' What this good spectrality is able to bring forth again in the living is the even more apparent calm and peaceful plurality that 'Sirissa becomes the victim who can speak for other victims, since the description of her fate is brought closer to life than that of Sailor (History of Sri Lanka in Anil's Ghost, 2017, 69).' Sirissa had become part of the organicized whole, reincarnated or actualized by the good spectralization of Ananda.

\section{Delirious Spectrality}

In terms of insistence, one can find another kind of spectrality that furthers the spectralities in Pramoedya's Buru Quartet: 'accordingly, the quartet only recognizes two kinds of specters. Good specters are ideals that cross the dividing line between death and life, are reincarnated, and remain once and for all on the side of the living. On the other hand, bad specters such as the colonial state and its apparatuses cross the border in the other direction (Cheah, 2003, 334).' Good spectrality however is only able to transcend bad spectrality but does not eradicate it altogether. In which case, the banishment or exorcising act is not directed at annihilating the techne of killings: what it does is to provide a fresh perspective, a radical finitude from a good spectrality that aestheticizes the field, seen in the open conclusion of the Buddha (re)constructions. What this means is that the idea of spectralization always operates on an insistence more originary than its other types. Following from good and bad spectrality, there is a more originary form.

Delirious spectrality is more originary than the other two forms of spectrality - as the sheer possibility of crossing the line between death and life, it is the condition of possibility of good and bad specters. Without originary spectrality, no crossing between life and death would be possible. To be sure, no ghosts would be possible. But by the same token, no exorcism of ghosts and, more importantly, no incarnation or actualization of spirit, no overcoming of finitude would be possible (Cheah, 2003, 334).

This delirious spectrality then is the original insistence form which the other types of spectrality operates, even, by extension, of plural and re-SriLankanized spectrality. If plural spectralization entails victimness as a natural characteristic of a dehumanized state and re-SriLankanized spectralization entails the cultural instrumentalities that are typical of Sri Lanka, delirious spectrality operates even before these two in a form of inhuman culture: 'we commonly understand culture as an alteration we introduce into nature through rational artifice. Spectralization is a form of inhuman culture, before culture and nature, that makes both possible (Cheah, 2003, 388).' Continues Cheah,

This inhuman techne or culture is the original ground of all historical instances of contamination and can lead to our infection by ideological images and other nonrecursive prostheses that facilitate political, economic, and cultural alienation (Cheah, 2003, 388).

In the spectral turn of the discourse, the same inhuman techne must be applied to rights as the original ground even before one can speak of it as 'human.' Rights must be unveiled of its originary insistence, its spectralization that makes possible all other types of spectralizations. It is a radical insistence that can be echoed from an interview of Ondaatje himself when he recounts an old myth: 
I remember reading the Indian myth, 'The King and the Corpse.' It's a strange, nightmarish tale about a king who ends up with a body round his neck that he has to be responsible for ...the king keeps burying the body, but he wakes up the next morning and it's round his neck again (Ondaatje, 2004: 251; as cited by Chakavorty, 2013, 555).

Something like this figuratively describes the insistence of this delirious spectrality. It is the disjointed and disjoining time - 'the invocation of the ghost, the revenant, that comes back to haunt the present - the central and most disruptive element of spectrality (Marsh, 2014, 294).' It is the immaterial specter that is unable-to-be spoken (cf. Jolly, 2004, 633), and yet troubles and activates the living (Germanou, 2013, 366). More concretely,

It can be likened to the tain of the mirror that allows a free subject, of which the people is a case, to reflect itself and to see and know itself in that reflection, and in that seeingknowing and return-to-self, incarnate and give life to itself. But the tain itself cannot be seen (Cheah, 2003, 334).

It propels and crosses the realms of victimness in plural spectrality, nationalized belongingness in re-SriLankanized spectrality, dehumanization of bad spectrality, and the reincarnating acts of good spectrality, giving these spectralizations a sense of original self-reflection towards those they further haunt. The idea is that all the other types of spectralizations took a form that describes the mechanisms of their spectrality, hence their modifiers. But the idea of spectralization per se took its name from delirious spectrality, which is a redundancy, because for spectrality to spectralize, it must be delirious.

In the text, something delirious happens, as it were, when one will say of Anil who operates like a specter 'to discover the source of the organized campaigns of murder engulfing the island (Vukcevic, 2005, 585).' One can speak of this in a plural spectrality in that she investigates a murdered victim for others because 'no one can tell who the victims are (AG, 13).' But the points of view of the other spectralizations can be seen here as well depending of the mechanisms that are in focus. It presupposes also that Anil can only do so in Sri Lanka, within a dehumanized representation, or on the prospect of transcending the source of the campaign as a form of critical interrogation to it.

But there is a direct exposition of this spectrality in the final scene of Sarath and Anil. After Anil presented her investigation only to be weakened in argument due to a wrong evidence, Sarath tells her: 'Take the skeleton I've given you and get in the van. Go back to the ship with Gunesena (AG, 128).' Though she insists, Sarath did something quite delirious in this act: 'He slapped her hard. He was aware of people on the periphery, her gasp, her face as if it contained fever (AG, 128).' And then there in the ship Anil found the full form of delirious spectrality in the recorded voice of Sarath:

I'm in the tunnel of the Armoury building. I have just a moment. As you can tell, this is not any skeleton but Sailor. It's your twentieth-century evidence, five years old in death. Erase this tape. Erase my words here. Complete the report and be ready to leave at five tomorrow morning. That's a seven-o'clock plane. Someone will drive you to the airport. I would like it to be me but it will probably be Gunesena. Do not leave the lab or call me (AG, 129; Italics mine). 
Is not this momentary insistence a final plea that turns Sarath into the delirious specter that is described in the text 'He [Ananda] and the woman Anil would always carry the ghost of Sarath Diyasena (AG, 138)'? The erasure of his words, of his very being, completes the spectralization where all the other types of spectralities can be seen. He became at once the crossing possibility in uncovering victimness when he became a victim, within Sri Lanka, able to give Anil the crucial evidence of the dehumanized surroundings, and reincarnated as the voice of nobody in the tape to be remembered only by those who know him and hold his memory dear. No one can call Sarath anymore because he had become erased in the picture, and yet he lingers in it as the text's delirious ghost. Within this frame, the discourse of rights in the text is problematized by an original delirious spectralization by Sarath, so that the focal spectral turn is directed as an insistence that he represented well throughout the text e.g. as Anil's partner, Palipana's student, Gamini's brother, especially as support for the evidence of human rights towards the end. Simply put, those who will have to look at rights in the text will have to deal with Sarath's ghost first, his delirious spectralization.

\section{References}

Anderson, M. (2008). “What Would Be on the Other Side?": Spectrality and Spirit Work in Toni Morrison's "Paradise". African American Review 42(2): 307-321.

Blanco, M. and Peeren, E. (2013). In Blanco, M. and Peeren, E. (Eds.), The Spectralities Reader: Ghosts and Haunting in Contemporary Cultural Theory (pp.xxx-xxx). London: Bloomsbury.

Babcock, D. (2014). Professional Intimacies: Human Rights and Specialized Bodies in Michael Ondaatje's Anil's Ghost. Cultural Critique 87, 6o-83.

Brogan, K. (1998). Cultural Haunting: Ghosts and Ethnicity in Recent American Literature. Charlottesville: UP of Virginia.

Cameron, E. (2008). Indigenous spectrality and the politics of postcolonial ghost stories. Cultural Geographies 15, 383-393.

Chakravorty, M. (2013). The Dead That Haunt Anil's Ghost: Subaltern Difference and Postcolonial Melancholia. PMLA 128(3), 542-558.

Cheah, P. (2003). Spectral Nationality: Passages of Freedom from Kant to Postcolonial Literatures of Liberation. New York: Columbia University Press.

Cheah, P. (2006). Inhuman Conditions: On Cosmopolitanism and Human Rights. London: Harvard University Press.

Chen, J. (2002). The Logic of Phantasm: Haunting and Spectrality in Contemporary Chinese Literary Imagination. Modern Chinese Literature and Culture 14(1), 231-265.

Clinton, A. (2012). Intuitions in Literature, Technology, and Politics: Parabilities (pp.21-21). United States: Palgrave Macmillan.

Derrida, J. (1994). Specters of Marx: the State of the Debt, the Work of Mourning, and the New International. Trans. Peggy Kamuf. New York: Routledge.

Germanou, M. (2013). 'The Dead are Still Looking at Us': Harold Pinter, the Spectral Face, and Human Rights. New Theatre Quarterly 29(4), 360-369.

Jolly, R. (2004). Spectral Presences: Narrating Women in the Context of South Africa's Truth and Reconciliation Commission. Canadian Journal of African Studies 38(3), 622-637 
Kamboureli, S. (2009). The Diaspora Writes Back: Cultural Memory and Michael Ondaatje's Anil's Ghost. In Maver, I. (Ed.), Diasporic Subjectivity and Cultural Brokering in Contemporary Post-colonial Literatures (pp. 27-39). UK: Lexington Books, Rowman \& Littlefield Publishers, Inc.

Marsh, S. (2014). Editor's Introduction. Untimely materialities: Spanish film and spectrality. Journal of Spanish Cultural Studies 15(3): 293-298.

Nayar, P. (2016). Human Rights and Literature: Writing Rights. USA: Palgrave Macmillan.

Ondaatje, M. (2000). Anil's Ghost. New York: Vintage.

Ondaatje, M. (2004). Interview by Maya Jaggi. Writing across Worlds: Contemporary Writers Talk (pp. 250264). London: Routledge.

Ratti, M. (2004). Michael Ondaatje's Anil's Ghost and the Aestheticization of Human Rights. Ariel: A Review of International English Literature 35(1-2), 121-139.

Sarkar, S. (2017). Of bicycles and bombs: assembling ecological testimonies of conflict in Michael Ondaatje's Anil's Ghost. Green Letter: Studies in Ecocriticism 21(1), 28-47.

Shin, H. (2013). Dialectic of Spectrality: A Transpacific Study on Being in the Age of Cyberculture 1945-2012. Unpublished Dissertation for Doctor of Philosophy, Department of Comparative Literature and the Committee on Graduate Studies of Stanford University.

The History of Sri Lanka in Anil's Ghost. (2017). Retrieved from https://dokumen.tips/documents/thehistory-of-sri-lanka-in-anils-ghost.html

Turcotte, G. (2008). Spectrality in indigenous women's cinema: Tracey Moffatt and Beck Cole. Journal of Commonwealth Literature 43(1), 7-21.

Vukcevic, R. (2005). Memory and Place in Michel Ondaatje's Anil's Ghost. In Place and Memory in Canada: Global Perspectives (pp. 585-593). Paluszkiewicz-Misiaczek, M., Reczynska, A., and Spiewak, A. (Eds.). Krakow: Polska Akademia Umiejetnosci. 